\title{
Japan may require labels on genetic food
}

[TOKYO] Japan has announced plans to introduce tough regulations that would require all food containing genetically modified organisms (GMOs) to be labelled as such, despite strong opposition from the domestic food industry and overseas food importers. Following a nationwide opinion poll that closed on 9 October, the government is expected to decide shortly on which of two alternative plans to adopt.

Under one version of its proposal, products that may contain protein and genetic material of GMOs would have to be labelled as such. This suggests that products such as maize and soybeans, which are mostly imported from the United States, as well as processed food containing such ingredients, would have to be tested.

The US government has already sent Trade Representative Charlene Barshefsky to Tokyo to discuss the issue. At a meeting last month with Shoichi Nakagawa, the Japanese agriculture minister, Barshefsky warned that the regulations could jeopardize trade relations between Japan and the United States.

Because it produces only 30 per cent of its own agricultural needs, Japan is highly dependent on imports, especially from the United States, which provides 80 per cent of Japan's total soybean supply and most of the 20 genetically modified products currently available in Japan.

The proposed regulations were announced by the Ministry of Agriculture, Forestry and Fisheries (MAFF) in August. They have generated widespread surprise, because an apparent deadlock between consumer groups and the food industry on GMO labelling had made it difficult for the ministry to reach a consensus.

Those most startled by the agriculture ministry's announcement were, ironically, members of its own committee on GMO food labelling, who had been discussing the issue since May last year.

Yasue Ito, a committee member and direc-

\section{UK environment report looks to the people}

[LONDON] The public should be more closely involved in setting local and national environmental standards if these are to be widely accepted, according to Britain's Roya Commission on Environmental Pollution.

In a report published last week, the commission is reluctant to make specific recommendations about how this should be achieved. But it stresses the general need for a "new approach to policy-making".

The commission is chaired by Sir Tom Blundell, head of the department of biochemistry at the University of Cambridge and former chief executive of the Biotechnology and Biological Sciences Research Council. Its report, Setting Environmental Standards, argues that both scientific evidence and social values need to be used in setting environmental standards. In the past, it says, the neglect of values and non-scientific opinions has resulted in poor public acceptance of environmental policies.

The report stresses that scientific assessments of environmental issues remain an important basis for decision-makers. But it says that such assessments should present a range of possibilities for action, rather than a single option.

"Scientists should not usurp the policymaker's role," says Clair Chilvers, an epidemiologist at the University of Nottingham and a member of the Royal Commission. Chilvers points out that in many cases, such as the disposal of the Brent Spar oil platform in the North Sea or the propagation of genetically modified crops, scientific assessment on its own failed to provide a firm basis for policy decisions, partly because it contained many uncertainties.

Decision-makers should recognize that the "requirement for sound science as the basis for environmental policy is not the requirement for absolute knowledge", says the report. They should also accept that there are bound to be "limitations and uncertainties" at each stage of a scientific assessment of an environmental issue.

In addition to the traditional procedure of direct, science-based, government regulation of environmental issues, new instruments should be introduced. The commission says these could include negotiated agreements between governments and industries or companies, and economic instruments, such as green taxes or charges.

To ensure that people's values, attitudes and opinions are adequately taken into account, the commission recommends that new methods should be added to the "relatively technocratic procedures" of setting environmental standards. These might include community forums, citizens' juries and consensus conferences.

The commission recommends that the UK Department of the Environment should incorporate such methods into the procedures for considering environmental issues and setting standards. The use of new methods for determining public values should also be "high on the agenda" for European institutions, says the report.

Quirin Schiermeier

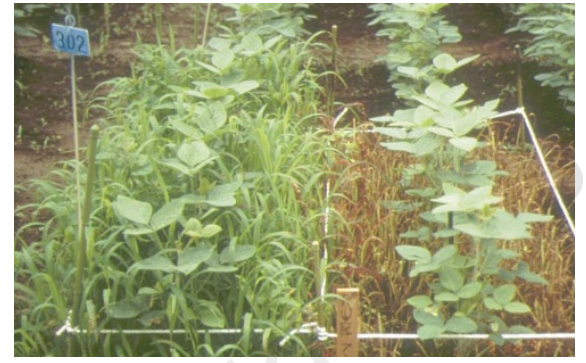

Telling signs: food would have to be labelled if it contained herbicide-resistant soya (right).

tor of the Consumer Science Federation, says the committee's discussions went only as far as whether the presence or absence of GMOs should be the basis of labelling.

"MAFF was meant to come up with a preliminary plan based on issues discussed by the committee, but instead we were presented with an outline of regulations involving issues we have never discussed," says Ito.

Strong lobbying from the food industry against GMO labelling had suggested that the ministry would agree that labels need only be used to indicate the non-use of GMOs. But MAFF has proposed two alternative plans, both of which involve labelling all food products containing GMOs, although in one case this would be mandatory and in the other it would be voluntary.

One plan stipulates that if the crop can be identified at an early stage as "genetically modified" or "non-genetically modified", the products resulting from such crops will be labelled accordingly; products resulting from the mixture of GMOs and non-GMOs would be labelled as "undifferentiated".

Meanwhile, representatives of the Japanese food industry are concerned about the difficulty of tracing original ingredients in processed food, as well as the potentially high cost of carrying out tests to identify products containing the DNA and proteins of GMOs. They also point out that there are no established techniques in Japan for testing for the presence of molecules from GMOs.

"It is technically possible to detect genetic material and protein of GMOs using a method based on the polymerase chain reaction," says Akihiro Hino from MAFF's National Food Research Institute. "The real problems are those associated with policy-making issues such as setting a lower limit for the presence of molecules from GMOs and dealing with the problem of contamination."

The ministry's decision on which version of its proposal to adopt is to be announced next month, based on the poll's results. "Public opinion will be the crucial factor in reaching our final decision, as the whole purpose of GMO labelling is to recognize the consumers' wish to know what they are eating," says a MAFF spokesman.

AsakoSaegusa 